\title{
Integrating qualitative research methodologies and phenomenology—using dancers' and athletes' experiences for phenomenological analysis
}

\author{
Susanne Ravn ${ }^{1}$ (D)
}

Accepted: 3 March 2021 / Published online: 3 May 2021

(c) The Author(s) 2021

\begin{abstract}
This paper sets out from the hypothesis that the embodied competences and expertise which characterise dance and sports activities have the potential to constructively challenge and inform phenomenological thinking. While pathological cases present experiences connected to tangible bodily deviations, the specialised movement practices of dancers and athletes present experiences which put our everyday experiences of being a moving body into perspective in a slightly different sense. These specialised experiences present factual variations of how moving, sensing and interacting can be like for us as body-subjects. To use of these sources inevitably demands that qualitative research methodologies - especially short-term ethnographical fieldwork - form part of the research strategy and qualify the way the researcher involves a second-person perspective when interviewing dancers and athletes about their experiences. In the subsequent phases analysing the data generated, I argue that researchers first strive to achieve internal consistency of empirical themes identified in the case of movement practices in question thus keeping to a contextualised and lived perspective, also denoted as an emic perspective. In subsequent phases phenomenological insights are then actively engaged in the exploration and discussion of the possible transcendental structures making the described subjective experiences possible. The specialised and context-defined experiences of 'what a moving body can be like' are accordingly involved as factual variations to constructively add to and potentially challenge phenomenological descriptions. Lastly, I exemplify how actual research strategies have been enacted in a variety of projects involving professional dancers', golfers' and sports dancers' practices and experiences, respectively.
\end{abstract}

Keywords Factual variation · Interviewing $\cdot$ Observations $\cdot$ Validity $\cdot$ Second-person perspective $\cdot$ Emic

Susanne Ravn

Sravn@health.sdu.dk

1 Department of Sports Science and Clinical Biomechanics, University of Southern Denmark, Campusvej 55, 5230 Odense M, Denmark 


\section{Introduction}

For decades, phenomenological thinkers have employed data from pathological cases to put normal, lived experiences into perspective. This is for example the case, when Merleau-Ponty (1962) analyses the bodily and perceptual capacities of the patient Schneider, when Shaun Gallagher (2005) makes a similar investigation of Ian Waterman, who suffers from a rare neurological condition, to discern various systems of bodily consciousness, ${ }^{1}$ or when Joel Krueger (2012) examines the Moebius syndrome to understand the importance of facial expressivity as foundational for empathy (Ravn \& Høffding, 2016). In methodological discussions, Zahavi (2005, 2013), Gallagher (2012), and Froese and Gallagher (2010) have emphasised that these kinds of pathological cases present real-life deviations that phenomenology can profit from. Empirical measurements from these cases offer rich sources of lived experiences valuable for phenomenological analysis. In Zahavi's description:

[empirical scientists] "do in fact pay quite a lot of attention to concrete phenomena and might consequently be less apt to underestimate the richness, complexity, and variety of the phenomena than the standard arm-chair philosopher" (Zahavi, 2013: 35).

This paper sets out from the hypothesis that the embodied competences and expertise characterising dance and sports activities also have the potential to constructively challenge and inform phenomenological thinking. As highly trained movement practitioners, dancers and athletes present real life variations or - to use the expression presented by Tom Froese and Gallagher (2010) - factual variations of how moving, sensing and interacting can be like for us as body-subjects. While pathological cases present experiences connected to tangible bodily deviations, the specialised movement practices of dancers and athletes present experiences which put our everyday experiences of being a moving body into perspective in a slightly different sense. As variations of 'what a moving body can be like', their practices and experiences highlight possibilities and aspects not immediately present to the movement, sensing and interactions which characterise everyday life (Legrand \& Ravn, 2009). However, while pathological cases can, to a certain degree, be defined by specific physical alterations to the body which can then be measured and tested by medical science, the identification and description of dancers and athletes as cases have a different starting point. The specialised incorporated skills and the 'richness, complexity and variety' of experiences so tethered to the practices of those skills, are in a fundamental sense part of social and cultural occurrences. Accordingly, the incorporated techniques of athletes and dancers, their ways of interacting, of using sense awareness and so on synchronously intertwine with social and cultural characteristics of their movement activities and the contexts of these specialised practices will have a profound bearing on experiences and the way such experiences can be described (e.g. Potter, 2008). In this article, I contend that exploring these specialised movement practices as empirical cases to be used for

\footnotetext{
1 Ian Watermann's way of dealing with his neurological condition was first described in the book Pride and the Daily Marathon written by Johathan Cole (1991).
} 
phenomenological analysis requires research methodologies that are sensitive to the contextual premises of experiences connected to these practices and, as I will explicate, this is exactly the distinct characteristics of qualitative research. In the argumentation and descriptions of how these explorations can take shape I will focus more explicitly on qualitative research strategies involving combinations of observations and interviewing. A combination which I, in the following, will also refer to as short-term ethnographical fieldwork.

The aim of this article is to indicate how we can use specialised forms of movement practice as factual variations in a phenomenological analysis by integrating ${ }^{2}$ qualitative research methodologies and phenomenology. Pursuing this aim, I shall firstly present a few phenomenological considerations on why and how experiences closely linked to specialised kinds of movement practices present intriguing factual variations for phenomenological analysis. This is followed by sections focusing on qualitative research: describing what it is, some overall considerations on the validity and reliability of short-term ethnographical methods and analysis, and the way rich descriptions are generated so that these have relevance for phenomenological analysis. In these sections, in the name of clarification, I also specify how the combination of short term ethnographical methodologies and phenomenology is different to the interview methods and analytical strategies of micro-phenomenology as well as to some of the applied phenomenological approaches dominating certain strands of qualitative research. Finally, I touch upon the analytical process that leads to the use of rich descriptions of dancers' and athletes' experiences in phenomenological analysis and present some examples on research projects based on data derived from artistic dancing, couple-based sports dance and golfing.

The article is based on a number of projects in which we (various colleagues and I) have integrated qualitative research and phenomenology in the analysis of various kinds of specialized movement practices. The methodological considerations and suggestions presented are grounded in a protracted analysis and condensation of the analyses performed in these projects. It is important for me to emphasise that the intention has not been to come up with a set of methodological doxas and specified 'steps' to take but to present central characteristics of qualitative research methodologies- and on this basis to indicate important aspects that should be considered when integrating short-term ethnographical fieldwork with phenomenological analysis in the case of specialised movement practices.

\section{Moving bodies are lived - and contextually embedded}

Merleau-Ponty, the phenomenologist of the body par excellence, emphasises motility as our basic intentionality (Merleau-Ponty, 1962, 1964). Movement and perception form a system that varies as a whole and that together comprise our very being in the world (Merleau-Ponty, 1962: 152). He further emphasises that what we move is never our objective body - for example, by bringing sense impressions and the different parts of the body together one by one - but our phenomenal body (ibid.: 106).

\footnotetext{
${ }^{2}$ I here use the descriptions 'integrating' as synonymous to 'interdisciplinary combination'.
} 
This is a body in which "the various parts of the body are known to us through their functional value only" (ibid.: 149) and the translations and unifications of different senses are the body itself (ibid.: 106, 148-149, 153). Merleau-Ponty also enables us to understand that the body is to be compared to the "general instrument of our "comprehension"" of being a body-subject in the world (ibid.: 235). He emphasises that the phenomenal body, in its livedness, is processual and that the lived body as this 'instrument of my comprehension' is interactively shaped.

Following Merleau-Ponty's descriptions, we know our lived bodies in relatively different ways. In concrete terms, ballet dancers know their body in quite different ways from rugby players or pianists. The ways the various part of the body in a practical sense are known will be reflected in the practitioners' ways of relating to and conceptualising their moving body, in the skills incorporated and the ways these skills present potentials for action, and, not least, in the various ways ingrained bodily postures, tensions and gestures form an ever present (back)ground for their acting, sensing and interacting. As Iris Young (2005) has critically pointed to in her analysis of a girl throwing, actual practices as they unfold in situated conditions also entail a bodily comportment that is secondary to those that are socially and culturally ingrained. Her analysis reminds us that lived bodies also entails aspects and dimensions not immediately visible to us. Thus, when we turn to dancers' and athletes' practices and experiences as cases which might show us what a moving body can be like, we should carefully consider that these practices and experiences do not only reflect a here and now of the actions unfolding. These cases of specialised movement practices also involve diachronic aspects of bodily comportments that silently condition the skills and actions in focus for the analysis.

That the experiences of our moving body are connected to a certain heritage informing our postures, tensions and gestures in complex ways has also quite recently been addressed by Evan Thompson. In his introduction to the second edition of The Embodied Mind (2016), he (self)critically points out that Buddhist meditation is to be viewed as an exercise of skilful practice and know-how and that it offers a skillful way of enacting certain kinds of embodied states and behaviours in the world (Thompson, 2016: xxiv). Comparable to dance and sports practices, meditation is a contextually embedded practice and, in Thompson words, it is accordingly a mediated experience. ${ }^{3}$ Thompson specifies the mediated aspect of experiences by drawing on anthropologist and social scientist Gregory Bateson's (1972) work on interaction and context and his explications of how communication unfolds on several levels simultaneously. Between others, Bateson exemplifies, ways in which metacommunicative aspects are central to being able to know if, for example, fighting is for play or for real (Bateson, 1972: 177-193). Adding to Thompson's point on the mediated aspect of the practice under investigation, Bateson's work facilitates clarifications of how diachronic perspectives are ingrained into the interactions of the here-and-now and offers a practice-connected approach to become specific in relation to what the interactive shaping of practices and experiences entails. To

\footnotetext{
3 To be precise, Thompson specifically points to that if we accepted the claim that Buddhist philosophy derives from meditation, we would end up ignoring the complex historical and interpretative issues that arise in trying to relate mindfulness meditation practices to Buddhist philosophies.
} 
know how to participate, when to do (and say) what, and how to notice the 'right' things in a situation characterise central aspects of the incorporated logics that are weaved into and constitute metacommunicative layers of actions and interactions. Bateson's work emphasises that practices and experiences are inextricably bound up with context. It thereby anchors Thompson's point concerning the mediated nature of practices and experiences to contextual matters. Contexts are profound to how practices are enacted, and it would simply be a mistake to aim at dissociating context from experience as if context constitutes a "satellite dimension" (Petitmengin et al., 2019) to the experiences in focus.

Taking Young's, Thompson's and Bateson's works into consideration, the methodological strategy presented in this article is firstly to generate rich descriptions by accepting that experiences as lived are simultaneously contextually embedded and based on ingrained bodily comportments. This means that when researching these experiences, the generation of rich descriptions should not only focus on the subject's inner feelings and thoughts but would also need to include descriptions of the interactions and actual situated perspectives embedding the experiences. By definition, these rich descriptions present subjective accounts of experiential content contingent to the actual practices. From thereon, in a second part of the research process, the strategy is to actively engage phenomenological insights when aiming at accounting for and (critically) discussing the possible structures that support and enable such experiences. In other words, we use a strategy in which we employ descriptions of the 'what' of experiences as data for analysing the possible 'how' of such subjective experiences. ${ }^{4}$

Generally, the methodological strategy for generating rich descriptions of these specialised practices thereby reflects the strategy as described by Høffding and Martiny (2016) in their article focusing on how to use interviews for phenomenological analysis. Following their descriptions, we should think of the first and the second part of the research process as two tiers. In the first tier, researchers are to generate rich descriptions in accordance with the rigor of qualitative research and then in the second tier they focus on the phenomenological analysis of these descriptions. As articulately described by Høffding and Martiny, the two tiers are each linked to their research paradigm - qualitative research and phenomenology, respectively - but also dialectically connected in the iterative process of generating and analysing descriptions of experiences. Important to the integrative strategy presented in this article, Høffding and Martiny (2016) highlight that the two tier strategy is quite different to the methodological approach presented in the Explication Interview (EI) (Bitbol \& Petitmengin, 2013; Petitmengin, 2006) and the Micro-Phenomenological Interview (MPI) (Petitmengin et al. 2019) which are based on a fairly elaborate framework for interviewing. The strategy of these closely connected approaches is to use the interview to employ a guided form of bracketing of the interviewee's experiences throughout the interview sessions. Accordingly, in the interview EI and MPI are already focused on generating descriptions that address the possible 'how's of the singular experience in focus and on revealing the structure of that experience. As recently emphasized by Petitmingen et al. (2019), the methodological aim of MPI has

\footnotetext{
${ }^{4}$ I here implicitly draw on Gallagher and Zahavi's (2008) introduction to phenomenology and the endeavour of the philosophical phenomenological tradition.
} 
been to develop an interview protocol that enables the interviewee to reenact and live the experience under investigation in the here-and-now of the interview, allowing her/him to describe part of her/his experiences which s/he would also experience under the "normal' conditions for such experience. However, as Petitmingen et al. (2019) emphasise, under normal conditions this part of experience is unrecognized by the subject interviewed (2019: 694).

By contrast and in accordance with the stance in this article, Høffding and Martiny argue that experience is not something we can retroactively return to. Rather, "it [experience] has no fixed diachronic stability, hidden inside the head ${ }^{5}$ to be dug up by memory, no Archimedian point of reference. It is embodied and enacted in the world together with other experiencing subjects" (2016: 544). The interview is not outside the flow of lived experiences. Experiences as described in the interview situation are part of a retrospectively oriented process, recalling experiences under the condition of the interview situation. Reflecting and describing experiences present an opening up of these experiences on new terms (Zahavi, 2011). ${ }^{6}$ Accordingly, the data generated form part of a co-generative process also involving, as a minimum, the interviewer and his or her ability to facilitate still richer descriptions of experiences (Ravn, 2009, Ravn \& Hansen, 2013). Before moving on to explicate how qualitative research presents appropriate approaches to handle such co-generative processes and, not least, the contextual embeddedness of the lived experiences in focus, let me also, however briefly, place the methodological strategy in this article in relation to current debates on qualitative research and phenomenology.

\section{Qualitative research and phenomenological analysis - a highly debated combination}

In a recent paper, philosopher Anthony Fernandez (2017) points out that phenomenology seems to claim an identity based on a specific methodology in use. He argues that the subject matter of phenomenological investigations should and could be better identified and proposes a differentiation between different layers of the subject matter under analysis. Taken together these layers are, each in their own way, central to the description of the overarching theme of phenomenology: "the structure of meaning or the structure of world-disclosure" (2017:3559). Fernandez does not deny that phenomenology is characterized by the methodologies in use, but from a philosophical standpoint highlights the fact that several aspects will influence the way a phenomenological analysis unfolds. In a phenomenological investigation, the subject matter in focus will necessarily influence the methods applied for the given study - the order and ways they are put to use (Schmicking, 2010).

Qualitative inquiries per se address a diversity of ways in which data can be generated. As evidenced by the structure of central handbooks and by the presentation

\footnotetext{
5 See Krueger, 2014 and Krueger and Overgaard, 2012.

6 As Høffding and Martiny writes: "Zahavi specifically discuss how reflecting and describing should not be seen as falsifications of originary or pre-reflective experience (Zahavi, 1999, 2011, 2015) and criticise the idea that pre-reflective experiences as if internal, something you can 'come into contact with' or get 'closer' to.".
} 
of methodological discussions, the methods chosen and the explicit ways these are combined are highly dependent on their subject matter, on the access the researcher has to relevant persons, groups and fields, and on the research questions and research interests at stake (e.g. Smith \& Sparkes, 2016b; Denzin \& Lincoln, 2011). Framed within this methodological background it seems paradoxical that many qualitative research studies have preferentially focused on applying a particular phenomenological methodology and insisted that in this process the employment of the epoché and phenomenological reduction is to take center stage (e.g. Allen-Collinson, 2011; Allen-Collinson \& Evans, 2019; Dale, 1996; Finlay, 2012; Giorgi, 1975, 1997, 2008; Kerry \& Amour, 2000). Following Fernandez' point that phenomenology tends to be presented as a specific methodology, it seems fair to note that this tendency has had contagious effects on how phenomenology has been applied in the academic fields of qualitative research.

Recent critique, especially from Zahavi, has pointed up serious misunderstandings in several of these applied versions of phenomenology (e.g. Zahavi, 2019a, 2019b; Zahavi \& Martiny, 2019). ${ }^{7}$ As echoed in Dahlberg and Dahlberg's (2020) sketch of Zahavi's critique, phenomenological ideas and concepts seem to be transposed and used as though they were "building blocks ready to use." The point here is not to recall elements of the harsh critique raised but to emphasize that Zahavi's (2019b) call for "ignoring the epoché," and encouragement to qualitative researchers to focus instead on using the phenomenological insights for the elucidation, analysis and discussion of the phenomenon in focus of their investigation, invites constructive discussions regarding how to engage phenomenology in qualitative research.

At this point, permit me to reiterate that this article is not aimed at discussing how phenomenology can be put to use in qualitative research but, conversely, focuses on discussing how qualitative research can be put to use, so that phenomenology can profit from cases of specialized movement practices. It is important to note however that it is fundamental to the methodological strategy presented here that these two strands of methodological interests are to be regarded as connected. That is, if we draw on the two-tier argumentative logic presented by Høffding and Martiny, we are interested in how description of practices and experiences can form the ground for analyses which unfold in accordance with the rigour characterizing sound philosophical phenomenological analysis. However, it is also central to the considerations presented here that using the same methodological strategy we can target academic fields of qualitative research. When doing so, phenomenological insights are then in use to better understand the experiential structures that potentially underlies and supports the contextualised and lived experiences in focus (Ravn, 2016). In more concrete terms this means that researchers would, for example, aim at analysing certain implicit aspects of subjective experiences by using phenomenological insights in ways that has value for the field of qualitative research. This has for example been

\footnotetext{
7 The part of Zahavi's critique concerning the 'phenomenology light' versions of application has also been critically discussed on several occasions in the fields of qualitative research. In the light versions, researchers seem to present phenomenology as if this is the best method to thoroughly describe subjective experiences. That is, several qualitative researchers have critically argued that, if we are to denote an investigation 'a phenomenological qualitative inquiry' it must as a minimum involve philosophical phenomenological descriptions and/or clarifications (Allen-Collinson, 2009; Finlay, 2009).
} 
the case in several studies where we (various colleagues and I) have analysed the actual ways the physicality of the body is present to different athletes and dancers. (e.g. Ravn, 2010; Ravn \& Christensen, 2014; Hjortborg \& Ravn, 2019; Bluhm \& Ravn, 2021). The results of these analyses are intended to have importance to coaches, athletes and dancers but might also potentially in a further analysis, present factual variations phenomenology can profit from. I will return to exemplify this connection by drawing on a specific investigation of the golfer's specialised use of bodily self-consciousness in the last section of this article.

\section{Qualitative research - basic methodological concerns}

Qualitative research presents an important methodological basis for a number of academic disciplines and each presents separate and partly distinct academic traditions for the way methods are used and mixed. As Denzin and Lincoln (2011) emphasize, qualitative research operates in a complex historical field and means relatively different things in each of the areas that constitute the historical fields of academia. Bearing this complexity in mind, they offer the following generic definition:

"Qualitative research is a situated activity which locates the observer in the world. Qualitative research consists of a set of interpretive, material practices that make the world visible. These practices transform the world. They turn the world into a series of representations, including fieldnotes, interviews, conversations, photographs, recordings and memos to the self. At this level, qualitative research involves an interpretive naturalistic approach to the world. This means that qualitative researchers study things in their natural settings, attempting to make sense of or interpret phenomena in terms of the meanings people bring to them." (Denzin \& Lincoln, 2011: 3, my italics)

As indicated throughout the definition, qualitative researchers deal with life as lived in context and engages in handling interpretative challenges throughout the processes of both generating and analysing descriptions of life as lived. Compared to the more specified methodological discussions which unfold in relation to specified analytical strategies, ${ }^{8}$ the methodological concerns I highlight here are no doubt more basic - and for researchers familiar with qualitative research tradition partially trivial. Nevertheless, these basic methodological descriptions are fundamental to understand what qualitative research can entail and which studies can count as qualitative research. Such descriptions have explicit relevance in relation to how one perceives and handles the validity criteria for analysing interviews.

Two closely linked features characterize fundamental methodological differences between qualitative inquiries and the quantitative based analyses which are used in, for example, the natural sciences. Firstly, as the qualitative researcher works on contextualized conditions, he/she cannot meet the criteria for repeatability that

\footnotetext{
${ }^{8}$ I here think of specific analytical strategies and discussions found in connection to, between others, Grounded Theory, thematic analysis and the different narrative analytical approaches (e.g. Smith \& Sparkes, 2016a).
} 
characterize quantitative oriented methods. To be more exact, in quantitative methodologies, instruments and methods are expected to be used in a standardized manner and in accordance with predetermined procedures so that measures are repeatable and consistent over time (Golafshani, 2003). In this setting, human emotions and experiential perspectives from subjects - and researchers - present undesirable biases, which disturbs repeatability. However, these kinds of 'bias' are exactly what is considered "essential and inevitable" to the qualitative researcher (Leung, 2015). For qualitative inquiry, emotions and experiential perspectives present the measures that are, to cite the generic definition, 'turned into a series of representations'. Accordingly, when qualitative researchers deal with different kinds of real-life practices and practitioners' subjective experiences of these, they are not expected to be able to present a one-to-one correspondence between what 'actually' happened in the situation and the data generated. Rather, they are expected to have faced the challenges of turning contextualized and situated activities and experiences into descriptions - or data - of relevance to the inquiry.

Secondly, like subjects interviewed and/or observed, the qualitative researcher is her/him-self in the world - and, as already indicated, part of the situation in which data are co-generated. Notes, descriptions and transcriptions are generated by the researcher 'being there', while forming part of and relating to these practices and experiences. The qualitative researcher has to realize that her/his own history, biography, gender, social class, ethnicity and so on cannot be neutralized but will influence the interaction and thereby the outcome in relation to the situated activity in focus for the study (Berger, 2015; Hammersley \& Atkinson, 2007; Thorpe \& Olive, 2016). ${ }^{9}$ The point to be emphasized here is not that the one position is superior than others for generating data; for example that one needs to be a dancer to thoroughly understand dancers' experiences. Rather the point is to highlight that from the very outset different researchers will adopt relatively different positions in relation to the practices under investigations and that these positions must be reflected in the analysis. $^{10}$

Kvale (2002) emphasised decades ago, in metaphorical terms, that qualitative researchers are not 'mine diggers' carving out data but are best described as 'explorers'. 11 The route they choose to take and the way they interact and attentively direct their awareness while taking this route (by, for example, combining observation and interview) will have a bearing both on the choice of practices and experiences explored and on the methods used (e.g. Strauss, 2000; Thorpe, 2012). While the route taken throughout the research can be relatively objectively described, the researchers' involvement in the situation demands (critical) self-reflexivity

\footnotetext{
9 With reference to Young's (2005) analysis of the throwing girl, the background of the researcher will also influence the ways in which s/he is aware of special characteristics of bodily comportment.

10 As I have discussed in other papers, the considerations on researcher positions presented here are in disagreement with Maxine Sheets-Johnstone's (2012) insistence that the researcher will need a dance background to understand dance and to follow an analysis of dancing. This methodological disagreement is discussed further in Ravn, 2009, ch. 2 and Ravn and Høffding (under review).

11 We are aware that the Danish word used by Kvale: 'opdagelsesrejsende' is often translated to 'traveler'. However, we find that the English term 'explorer' much better covers the original meaning addressed in Kvale's original discussions on interview methods.
} 
throughout the research process and, not least, transparency in relation to how selfreflexivity is put into use throughout. ${ }^{12}$

\section{Validity and reliability of qualitative research}

As emphasised in the former section, qualitative researchers link to a complex historical field of academic traditions and related epistemologies and consequently questions about validity form part of ongoing discussions spanning the diversity of interests and research paradigms identified within qualitative research (Denzin \& Lincoln, 2011: 11). Let me therefore note that, in the following, I focus specifically on the way validity and reliability is considered in relation to ethnographical oriented studies and the majority of case ${ }^{13}$ studies (e.g. Cho \& Trent, 2006; Hammersley \& Atkinson, 2007).

Generally speaking, the validity of qualitative research will be expected to reflect the appropriateness of methods in use to answer the research question in focus (Lincoln et al. (2011). It concerns the trustworthiness of the investigation including the consistency with which the different kinds of choices are made throughout the research process - from the epistemology underpinning the understanding of phenomena, the research questions raised, to the ways data are generated and analysed (Tracy, 2010). Specified in the discussion of Cho and Trent (2006) concerning trustworthiness, major validity will be focused on the transactional aspects of methods in use. That is, the researcher is expected to ensure that the

"interactive process between the researcher, the researched, and the collected data is aimed at achieving a relatively higher level of accuracy and consensus by means of revisiting facts, feelings, experiences and values or beliefs interpreted" (Cho \& Trent, 2006: 321).

When focusing on the cases of dancers' and athletes' experiences, transactional aspects of validity will depend on the ways in which the researcher creates good possibilities for being able to follow the descriptions of experiences on the premises of the dancers' and athletes' actual practices in the process of generating and analysing descriptions. That is, the ways in which the researcher adopts an openended, non-objectifying and self-reflective perspective - also addressed as a second person perspective (Varela \& Shear, 1999) - in relation to the dance and sports practices in focus. Practices which are contextually embedded through and through. Accordingly, the researcher must actively consider a research strategy which creates opportunities to follow descriptions from a second-person perspective on the premises of the actual practices - as contextualised practices. Observations present an obvious choice to include in the strategy - or design - of such studies. In different

\footnotetext{
12 Such self-reflexive considerations, and the ways these are inherently ingrained in the academic traditions which the researcher forms part of, interestingly link to ontological and epistemological questions discussed recently in philosophical anthropology (Pedersen, 2020; Throop, 2018). The relatively restricted space of this article does not allow for a discussion on these philosophical anthropological arguments and their relevance for the methods discussed in this article.

13 Short-term ethnographical fieldwork is generally understood as a specific kind of strategy or design for case studies (Flyvbjerg, 2011; Hodge \& Sharp, 2016).
} 
ways, depending on how observations are performed, they will create opportunities to come to learn about the implicit logic used to, for example, structure the training, and the ways concepts and particular kinds of wordings are used to address specific aspects of the movement practices and so on.

The transactional aspects of validity will entail that the researcher self-reflexively considers how her subjectivity has been involved in the generation of rich descriptions of the athlete's and dancer's world (Ravn, 2017a). It includes an awareness of how one becomes attuned to the moving body in new ways. This is not an easy task but involves ongoing considerations that lie beyond relatively obvious statements about one's prior experiences and immediate prejudices related to the practices in focus. Compared with the researcher's attunement to ways of moving, interacting and living by participating in the everyday lives of others over longer periods spanning several months or years in anthropological oriented ethnographical fieldwork (Throop, 2018), ${ }^{14}$ the short-term ethnographical fieldwork demands that the researcher considers more active ways of attuning herself to the practice in focus. On short-term premises, these transactional aspects of validity can between others be facilitated by constructively using different versions of researcher triangulation, ${ }^{15}$ for example, by involving peers to critically read the ongoing analysis to point out if implicit meanings and relatively esoteric concepts and descriptions could be further described in follow up interviews and/or if certain aspects of experience tend to be ignored in the analysis (e.g. Ravn, 2009; Ravn \& Hansen, 2013). Furthermore, the strategies for how observations and interviews are carried out and combined throughout the study, might in case specific ways also constructively add to heighten transactional validity. An example of how this can be carried out is presented in the later example of how the diversity of professional dancers was used actively in the way investigation was organised as a multi-sited ethnographical field-study.

Reliability is best evaluated in relation to the transparency of how the investigation is performed. That is, the various phases and the steps taken should be transparent to intersubjective corroboration. It should be possible to follow all the choices taken and the methods used during the process. Reliability and validity are closely interlinked. So, for example, following Burke's (2016) discussions, the reliability of qualitative research can, like validity, be addressed as a matter of its trustworthiness. Notably, when trustworthiness concerns reliability, it addresses the way methods and analysis are handled. To further the close link, Golafshani (2003) emphasises that if validity is replaced by the idea of trustworthiness then reliability is the consequence of validity handled in the study.

Let's return, however briefly, to the way validity is addressed in EI (Bitbol \& Petitmengin, 2013; Petitmengin, 2006) and MPI (Petitmengin et al., 2019). In these works, the validity of statements about experience should be measured in relation

\footnotetext{
14 In philosophical anthropological discussions Throop 2018 describes the anthropologist's attunement to new horizons of understanding in ethnographical fieldwork by emphasising that this attunment must be grounded in an interest into understanding the other through an engagement of "lateral displacement that enables one to critically reconsider one's views from another vantage point" (Jackson, 2013: 262). In the philosophical anthropological discussions these descriptions of how a second person perspective is to be brought are closely aligned with phenomenology and addressed as an ethnographical epoché.

15 Triangulation is here used in a relatively loose sense to address that a multiple method and/or multiple analytical strategy is involved to critically think with the descriptions generated.
} 
to a performative and not a "correspondentist" view (Petitmengin et al., 2019: 697). These specialized interview methods thereby at first impression seem to reflect the way validity is discussed and dealt with in the domain of qualitative research. However, unlike discussions of rigour in qualitative research, the researchers behind EI and the MPI continue to emphasize that reliability is to be measured in relation to the performative consistency of how the interview is performed against the elaborated framework and relatively detailed instructions of the methods. Reliability, for example, is to be judged by assessing whether questions are posed in accordance with the EI or MPI framework. Petitmengin et al. (2019) also emphasise that the focus of MPI and analysis on the structural elements of the experience under study allows reproducibility of analysis results (ibid.: 701). Furthermore, they emphasize that "the focalization of most qualitative methods on the contents of experience rather than on structures makes this reproducibility more difficult or even impossible" (Petitmengin et al., 2019: 701). Statements like this seem to insist that reliability is to reflect the criteria concerning reproducibility characterising quantitative based measurements. Petitmengin et al. thereby ignore the discussion in qualitative research on approaching reliability and validity on different terms than quantitative measures. To put it bluntly, they make comparison with qualitative research using false criteria. In general terms qualitative researchers will be expected to take great care not to circumvent but to address the condition of lived experiences while insisting on transparency in showing how contextual aspects and interpretation have been taken into account in the process of generating and analysing data.

\section{From the within-case consistency of practitioners' experiences to phenomenological themes}

In the ongoing analysis, I suggest the researcher will continue scrutinizing the data on the contextual condition of the actual practices. Accordingly, s/he is to focus on identifying significant characteristics of experiences and ideas which are central to the dancers or athletes while still adhering to the validity criteria of qualitative research. This includes that descriptions and notes are organized into themes that concern different aspects of the practitioners' experiences. The identification of these themes - and possible categorization of them - generally unfold as part of an iterative process in which the researcher reflexively re-questions themes and categories and if different themes belong in the same group. Let me emphasise that phenomenological themes are not directly expressed in the themes and categories identified at this point of the analysis. Rather, it is in the following phases of analysis that the dancer's or athlete's experiences are used as factual variations for a phenomenological analysis. In that sense, while the first phase of analysis is focused at achieving internal consistency for the within-case descriptions of the practitioner's embedded experiences the later phase is focused on engaging phenomenology to point to invariants that are structural to the experiences described. 
In the first phases of analysing data the researcher should stay with describing themes so that these, as closely as possible, accord with the contextual and lived conditions of the subject's practices. In pragmatic accordance with ethnographical and cultural analytical considerations, descriptions should thereby be handled in accordance with significant indigenous themes. This can also be addressed as using an 'emic' approach. In Kenneth Pike's introduction of the term for linguistic analysis, emic accounts are (sub)culturally bound while its counter term 'etic' adheres to descriptions of phenomena that apply across cultures and which accordingly also reflects theoretical ideas of the analysists (Morris et al., 1999; Peterson \& Pike, 2002). ${ }^{16}$ As emphasised earlier in this article, there is no neutral stance from which to generate data, and a solely emic perspective is impossible as every researcher always brings an inescapable subjectivity and lived experience to the study (Morris et al., 1999; Olive, 2014). Furthermore, as has been pointed to in discussions of the two terms, proportions of either substantive theory and/or methodological theory about how to go about conducting a process of reflecting contrasts between emic and etic perspectives will also influence the research process (Peterson \& Pike, 2002: 15). So, to focus on using an emic approach does not present a methodological solution to how to achieve robust transactional validity. Rather, I suggest the term is understood as a methodological oriented tool which can help keep focus on the indigenous perspective of experiences.

\section{The research strategy in use - two examples}

The following two examples - spanning three different research projects - exemplify how the methodological considerations presented in this article are put into play in research projects. Especially how each project called for specific methodological considerations and choices. The three projects briefly presented, have been carried out with various colleagues - philosophers and/or qualitative researchers. Reflecting the discussions in the article I specifically focus descriptions on a) the design of the investigations, b) the handling of the second-person perspective in the research process to create optimal transactional validity between practices and experiences in focus and the data generated, and c) the phenomenological topic in focus for the analyses.

\subsection{On dancers' bodily self-consciousness}

In this project we aimed to investigate bodily self-consciousness in the case of skilled movement practitioners - more specifically: how the physicality of the

\footnotetext{
16 The terms emic and etic are originally developed in linguistics by Kenneth L. Pike for cross-linguistic/ cultural analysis but are today adapted into other fields of research - including ethnography. One finds relatively different versions and tense discussions of the terms across the fields in which it has been brought to use (e.g. Harris, 1976; Peterson \& Pike, 2002). I here use the terms in accordance with both Peterson and Pike's (2002) discussion and the way it is used in ethnography (e.g. Olive, 2014).
} 
body can be present to practitioners' awareness ${ }^{17}$ (Ravn, 2009; Legrand \& Ravn, 2009). The practices of professional dancers were considered especially interesting cases, as these specialised movement practitioner's both explore and train the physical body (the possibilities it opens and limits) as well as engage their bodily experiences quite actively in relation to these physical explorations (e.g. Potter, 2008; Rouhiainen, 2003).

Two circumstances played a central role for how the overall design of the research project and the handling of the second-person perspective took shape. Firstly, recognising the diversity of dance practices characterising professional dance in a European context, it was important from the beginning to aim at including relatively different genres and styles of dance practices in the artistic field. Thus, a total of 13 dancers from different cities in Europe were involved in the research project which, accordingly, was organised as a multiple-sited fieldwork (Amit, 2000). This meant that the different field sites involved can be viewed as an intersection of professional dancers and their practices within the shifting terrain they form part of (Strauss, 2000) and that the fieldwork was organised around the places and settings where the dancers worked. Geographically, it accordingly took place in Copenhagen, London, Amsterdam, Malmo, Brussels and Vienna. The dancers were in different ways and with different preferences trained in ballet, improvisation and/or various contemporary dance styles. Data was generated through series of short-term fieldwork, typically of one week. It included a formal interview which was prepared on the basis of the fieldwork. This was generally repeated twice with each of the dancers (Ravn, 2009: 118-120).

Secondly, as the researcher had a background in professional dance herself, her embodied dance experiences was used in an activist fashion to form a resource in observation by actively forming part of the training. Thus, the researcher's observations and participation were used to prepare formal interviews. This meant that the dancers were asked to describe their practices and experiences of these practices in accordance with the structures and contexts of the actual practices. Often concrete situations from the practices were included in the questions to both invite further descriptions in relation to experiences (see also Ravn and Hansen, 2013). In this way, the interview approach depended on an attentive listening position from the researcher's side (Thorpe, 2012) and involved an openness for interviews to develop into active dialogues. (e.g. Holstein \& Gubrium, 1995; Taylor \& Bogdan, 1998: 105). In these active dialogues the researcher at times used her own first-person experiences of the practices to elicit further descriptions from the dancer.

However, the researcher's familiarity with the practices being studied also involved careful consideration of how to set up a design in which some of the dancers' practices could allow the researcher to cast constructive doubt and to find ways to defamiliarize herself with her own experiences of dancing. The idea was to enable her to take up an open-ended and self-reflexive stance adhering to a second person perspective without ending up resonating her own first-person perspective of the same kind of dancing to such a degree that it overshadowed the specificity of

\footnotetext{
17 The whole project began as an explorative investigation of the dancers' techniques - and how the materiality of the body is dealt with. The phenomenological theme concerning bodily self-consciousness was specified in close collaboration with contemporary phenomenological discussions - especially Legrand's work (2007a, b).
} 
the interviewee's descriptions. Furthermore, on several occasions data and analysis were discussed with another researcher who was not herself a dancer. These discussions were especially used in between interviews and to prepare for follow up interviews (Ravn \& Hansen, 2013).

In the subsequent phases of the analysis the multiple field study was handled as a multiple case study in the sense that, when identifying central themes for coding, the data on each dancer's experience was analysed on its own terms. Thereby coding categories were developed based on induction for each dance practice and on the contextual embeddedness characterising each of the practices. In this phase of the analysis, interview transcriptions were also processed into condensed versions to help follow each of the professional dancers' descriptions of the contextualised conditions of the specific dance field they formed part of. These took form as abbreviated versions of the transcript in which irrelevant descriptions were taken out and certain characteristics of spoken language, such as repetition and unfinished sentences, were also removed or transformed into more readable text, while taking care to formulate sentences as faithfully as possible to the words and descriptions presented by the dancer. Checking the validity of the descriptions generated included each dancer being invited to accept, comment, and/or adjust the edited interview so that it accorded with the dancer's report of the central part of his/her experiences in movement (Ravn, 2009: $141 \mathrm{ff}$.). These edited transcriptions, alongside the original full transcription and observational notes, were included in the case-specific analyses describing central themes important to the dancer's experiences. What especially stood out was that the dancers in each their way described how they had to feel their body in a certain way to dance well. The specific ways of feeling the body was then contingent to the techniques and styles in which the dancer trained and performed. For the ballet dancers this feeling of their bodies was centered round feeling aligned and placed, for one of the improvisers it was absolutely necessary to "feel weighted" to be able to improvise and for the dancer specifically drawing on Body-Weather training (a Butoh related dance practice) it was necessary to feel grounded to being able to be in contact with the energy transformation central to her expressive dance activities (Ravn, 2009, 2017b).

In the following phase of phenomenological analysis, we focused on these different kinds of feelings of their bodies to see if certain experiential structures were recognizable across the variety of the dance practices and specifically involved Legrand's (2007a, 2007b) phenomenological analysis of bodily self-consciousness. As a result of this part of the analyses we proposed that "a form of experience of the body's subjectivity which is perceptual but not reifying" presents a special kind of pre-reflective performative bodily self-awareness (Legrand \& Ravn, 2009: 405). Further and not least that this kind of pre-reflective performative self-awareness is to be considered a central part of the dancers' expertise.

\subsection{The reciprocity of interaction in elite sports dance and bodily self-consciousness in golfing}

In this second example I draw upon two different projects which involved similar setups. In the first study we aimed at continuing the investigation of 
bodily self-consciousness to see if the kind of pre-reflective performative dimension described in the study with dancers could also be present in athletes' experiences - or more precisely for an elite golfer's awareness of her body when training. At the same time, however, if confirmed, we wanted to also discuss what could be the potential value of such phenomenological insights for future analysis of golf training. The other study focused explicitly on exploring the reciprocity of shared experience in the face to face encounter of dancing together (He \& Ravn, 2018). Primarily building on Zahavi's (2015), Zahavi and Rochat's (2015) and León and Zahavi's (2016) work on this phenomenological topic, we were interested in investigating if or how such reciprocity of shared experiences could be trained and possibly strategically used by athletes involved in couple based sports - in concrete two couples of sports dancers competing in the absolute world elite.

In both cases the phenomenological topic of interest was clearly sketched out from the beginning and the overall design framing the research strategies were alike. More specifically, both cases of practices could be considered "crucial cases" (Hodge \& Sharp, 2016), which in overall terms refers to that the case holds the potential to constructively challenge the insights and theories forming a central background of the study. As emphasised in sociologist Bent Flyvberg's often quoted work on the value of case studies, crucial cases can help us to "understand the limits of existing theories and to develop new concepts, variables, and theories that are able to account for deviant cases" (2011: 307). Like the case of the girl throwing (Young, 2005) cases can be carefully chosen with the specific aim of further exploring phenomenological descriptions of specific topics. Metaphorically speaking, the cases potentially present examples of there being 'black swans' and thereby prove that not all swans are white (Flyvbjerg, 2011).

In these two investigations I (performing the fieldwork) did not have an embodied familiarity with the practices in focus, as was the case in the investigation of the 13 professional dancers' technical expertise. Observations were thus performed by sitting at the side and more passively observing the golfer and the sports-dancers' practices of training. Other aspects were also alike: Both the golfer and the sportsdancers had a very tight schedule involving much travel, participation in tournaments and so on, so a short term ethnographical field work was performed by following the everyday training on five to seven occasions spread out over a period of a couple of months. In the formal interviews, a variety of examples based on the observed practices was used as an opener to invite the golfers and sports dancers, respectively, to describe practices and experiences in detail. Again, great care was taken that formal interviews were developed from the contextualized condition of the practitioners' experiences. This included that words and concepts were strived to be used on emic terms throughout the interview and the first phases of analysis. In similar fashion to the way of heightening validity in the case of dancers described in the former example, the golfer and sport dancers were invited to read and comment on their interview transcripts in between interviews.

The single case study of the golfer was from the outset aimed at contributing to fields of qualitative research. Thus, we used phenomenological insight on the different dimensions of bodily self-consciousness as explicated in the phenomenological analysis of the professional dancers to critically elucidate on the golfer's ways of 
being aware of her body while training to optimise her skills. The study pointed out that current golf literature is based on a theoretical understanding of bodily selfconsciousness which is too narrow or simple compared to the understanding we could offer by involving recent phenomenological insight on the structure of bodily self-consciousness. Thus, based on our analysis we suggested that golf coaches revise the theoretical background they use when analysing and assisting golfers in improving their skills. Although not explicitly addressed in the result of the analysis it's here relevant to add that the investigation of the golfer's ways of being aware of her body from a phenomenological point of view adds to both confirm and further exemplify how a special kind of pre-reflective performative bodily self-awareness is important to movement practitioners.

In accordance with Zahavi's descriptions of the bi-directed nature of shared experience, the analysis of the elite sports-dancers exemplified how this kind of reciprocity can unfold in highly specialised practices and presented detailed descriptions of how this bi-directedness can unfold in an ongoing dynamics of two separate flows of movement (He \& Ravn, 2018). However, beyond confirming the very outset for the analysis, the practices of the two couples also uncovered that reciprocity can be deliberately shaped through the mutual coordination and affective bound dynamics of the dancers' movement. In other words, the analysis of these movement specialists indicates the possibility that reciprocity can be actively modified through movement by the subjects involved in the shared experience.

\section{In conclusion}

The specialised movement practices of dancers and athletes are contextualised through and through. To use these practices and related experiences as factual variations of 'what our moving body can be like' for us in a phenomenological analysis, we have insisted that the contextual embeddedness can and should not be avoided in the process of generating data. Rather, the researcher should turn to qualitative research methodologies and take great care to be transparent in how translational validity is handled in the process of generating data of practitioners' experiences on the lived conditions these practices are a part of.

The research strategy we have presented has focused on integrating qualitative research methodologies and phenomenology. It accordingly embraces the two-tier research strategy presented in the 'phenomenological interview' by Høffding and Martiny (2016). Yet, discussing the research strategy in use by involving thorough elucidation of the generic ground and rigor of qualitative research, the article has moved beyond describing only the interview situation and targeted essential challenges which are to be handled when integrating short-term ethnographical fieldwork and phenomenology. Discussions have especially contributed to highlight how the second-person perspective can be handled so that high transactional validity is achieved between dancers' or athletes' actual experiences and the data generated. In close connection to these discussions the article accentuated the need for carefully considering the design of research projects. Especially, how the design frames the possibilities for how the second person-perspective can be brought in to use. 
The examples presented, each in their case-specific way, demonstrate how factual variations of 'what a moving body can be like' can add to and constructively challenge phenomenological descriptions. At the same time the examples also demonstrate that the contextual premises of the practices in focus demand the researcher to situate the research strategy in good accordance with the lived experiences under investigation.

Open Access This article is licensed under a Creative Commons Attribution 4.0 International License, which permits use, sharing, adaptation, distribution and reproduction in any medium or format, as long as you give appropriate credit to the original author(s) and the source, provide a link to the Creative Commons licence, and indicate if changes were made. The images or other third party material in this article are included in the article's Creative Commons licence, unless indicated otherwise in a credit line to the material. If material is not included in the article's Creative Commons licence and your intended use is not permitted by statutory regulation or exceeds the permitted use, you will need to obtain permission directly from the copyright holder. To view a copy of this licence, visit http://creativecommons.org/licen ses/by/4.0/.

\section{References}

Allen-Collinson, J. (2009). Sporting embodiment: sports studies and the (continuing) promise of phenomenology. Qualitative Research in Sport and Exercise, 1, 279-296.

Allen-Collinson, J. (2011). Intention and epoché in tension: Autoethnography, bracketing and a novel approach to searching sporting embodiment. Qualitative Research in Sport, Exercise and Health, $3(1), 147-168$.

Allen-Collinson, J., \& Evans, A. B. (2019). To be or not to be phenomenology? That is the question. European Journal for Sport and Society, 16(4), 295-300.

Amit, V. (2000). Introduction: Constructing the field. In V. Amit (Ed.), Constructing the Field. (pp. 1-18). Routledge.

Bateson, G. (1972). Steps to an Ecology of Mind. Chandler Publishing Company

Berger, R. (2015). Now I see it now I don't: Resercher's position and reflexivity in qualitative research. Qualitative Research, 15(2), 219-234.

Bitbol, M., \& Petitmengin, C. (2013). A defense of introspection from within. Constructivist Foundations, 8, 269-279.

Bluhm, K., \& Ravn, S. (2021). 'It has to hurt': A phenomenological analysis of elite runners' experiences in handling non-injuring running-related pain. Qualitative Research in Sport, Exercise and Health. (Published online: 31 March 2021).

Burke, S. (2016). Rethinking 'validity' and 'trustworthiness' in qualitative inquiry: How might we judge the quality of qualitative research in sport and exercise sciences? In B. Smith \& A. Sparkes (Eds.), Routledge Handbook of Qualitative Research in Sport and Exercise (pp. 330-340). Routledge.

Cho, J., \& Trent, A. (2006). Qualitative Research, 6(3), 319-340.

Cole, J. (1991). Pride and the daily marathon. Bradford Books.

Dahlberg, H., \& Dahlberg, K. (2020). Phenomenology of science and the art of radical questioning. Qualitative Inquiry, 26(7), 889-896.

Dale, G. A. (1996). Existential phenomenology: Emphasizing the experience of the athlete in sport psychology research. The Sport Psychologist, 10, 307-321.

Denzin, N. K., \& Lincoln, Y. S. (2011). Introduction: The discipline and practice of qualitative research. In N. K. Denzin \& Y. S. Lincoln (Eds.), The SAGE Handbook of Qualitative Research, 4 (pp. 1-20). SAGE.

Fernandez, A. V. (2017). The subject matter of phenomenological research: Existentials, modes, and prejudices. Synthese, 194, 3543-3562.

Finlay, L. (2009). Debating phenomenological research methods. Phenomenology and Practice, 3, 6-25. 
Finlay, L. (2012). Unfolding the phenomenological research process: Iterative stages of "seeing afresh." Journal of Humanistic Psychology, 53(2), 172-201.

Flyvbjerg, B. (2011). Case study. In N. K. Denzin \& Y. S. Lincoln (Eds.), The SAGE Handbook of Qualitative Research, 4. (pp. 301-316). SAGE.

Froese, T., \& Gallagher, S. (2010). Phenomenology and artificial life: Toward a technological supplementation of phenomenological methodology. Husserl Studies, 26(2), 83-106.

Gallagher, S. (2005). How the body shapes the mind. Clarendon Press.

Gallagher, S. (2012). Taking stock of phenomenology futures. The Southern Journal of Philosophy, 50, 304-318.

Gallagher, S., \& Zahavi, D. (2008). The phenomenological mind. Routledge.

Giorgi, A. (1975). An application of phenomenological method in psychology. In A. Giorgi, C. Fischer, \& E. Murray (Eds.), Duquesne studies in phenomenological psychology. (Vol. 2, pp. 82-103). Duquesne University Press.

Giorgi, A. (1997). The theory, practice, and evaluation of the phenomenological method as a qualitative research procedure. Journal of Phenomenological Psychology, 28, 235-260.

Giorgi, A. (2008). Concerning a serious misunderstanding of the essence of the phenomenological method in psychology. Journal of Phenomenological Psychology, 39, 33-58.

Golafshani, N. (2003). Understanding reliability and validity in qualitative research. The Qualitative Report, 8(4), 597-606.

Harris, M. (1976). History and significance of the emic/etic distinction. Annual Review Anthropology, 5, 329-350.

Hammersley, M., \& Atkinson, P. (2007). Ethnography: Principles in Practice. $3^{\text {rd }}$ ed. Routledge.

He, J., \& Ravn, S. (2018). (shared authorship). Sharing the dance: On the reciprocity of movement in the case of elite sports dancers. Phenomenology and the Cognitive Sciences, 17, 99-116.

Hjortborg, S. K. \& Ravn, S. (2019). Practising bodily attention, cultivating bodily awareness - a phenomenological exploration of tai chi practices. Qualitative Research in Sport, Exercise and Health, 12(5), 683-696.

Hodge, K., \& Sharp, L. (2016). Case studies. In B. Smith \& A. Sparkes (Eds.), Routledge Handbook of Qualitative Research in Sport and Exercise. (pp. 63-74). Routledge.

Holstein, J. A., \& Gubrium, J. (1995). The Active Interview. Sage Publications.

Høffding, S., \& Martiny, K. (2016). Framing a phenomenological interview: What, why and how. Phenomenology and the Cognitive Sciences, 15(4), 539-564.

Jackson, M. (2013). Where thought belongs: An anthropological critique of the project of philosophy. In lifeworlds: Essays in existential anthropology. University of Chicago Press.

Kerry, K. S., \& Armour, K. M. (2000). Sport sciences and the promise of phenomenology: Philosophy, method, and insight. Quest, 52(1), 1-17.

Krueger, J., \& Overgaard, S. (2012). Seeing subjectivity: Defending a perceptual account of other minds. ProtoSociology, 47, 239-262.

Krueger, J. (2014). Emotions and other minds. In R. Campe \& J. Weber (Eds.), Interiority/exteriority: Rethinking emotion. (pp. 323-349). Walter de Gruyter.

Kvale, S. (2002/1994). Interview - En introduktion til det kvalitative forskningsinterview. Hans Reitzels Forlag.

Leung, L. (2015). Validity, reliability, and generalizability in qualitative research. Journal of Family Medicine and Primary Care, 4(3), 324-327.

Legrand, D. (2007a). Pre-reflective self-as-subject from experiential and empirical perspectives. Consciousness and Cognition, 16(3), 583-599.

Legrand, D. (2007b). Pre-reflective self-consciousness: on being bodily in the world. Janus Head Issue: The Situated Body, 9(1), 493-519.

Legrand, D., \& Ravn, S. (2009). Perceiving subjectivity in bodily movement: The case of dancers. Phenomenology and the Cognitive Sciences, 8, 389-408.

León, F., \& Zahavi, D. (2016). Phenomenology of experiential sharing: The contribution of Schutz and Walther. In Salice, A., \& Schmid, H. B. (Eds.), The phenomenological approach to social reality: History concepts, problems (pp. 219-234). Springer.

Lincoln, Y. S., Lynham, S. A., \& Guba, E. G. (2011). Paradigmatic controversies, contradictions, and emerging confluences, revisited. In N. K. Denzin \& Y. S. Lincoln (Eds.), The SAGE Handbook of Qualitative Research, 4. (pp. 97-128). SAGE.

Merleau-Ponty, M. (1962/1998). The phenomenology of perception. Routledge. 
Merleau-Ponty, M. (1964). The primacy of perception - and other essays on phenomenological psycology, the philosophy of art, history and politics. Northwestern University Press.

Morris, M. W., Leung, K., Ames, D., \& Lickel, D. (1999). Views from inside and outside: Integrating Emic and Etic Insights about Culture and Justice Judgment. The Academy of Management Review, 24(4), 781-796.

Olive, J. L. (2014). Reflecting on the tension between emic and etic perspectives in life history research: lessons learned. Forum: Qualitative Social Research, 15, 2, art. 6.

Pedersen, M. A. (2020). Anthropological Epochés: Phenomenology and the ontological turn. Philosophy of the Social Sciences, 50(6), 610-646.

Peterson, M. F., \& Pike, K. L. (2002). Emics and Etics for organizational studies: A lesson in contrast from linguistics. International Journal of Cross Cultural Management, 2(1), 5-19.

Petitmengin, C. (2006). Describing one's subjective experience in the second person: An interview method for the science of consciousness. Phenomenology and the Cognitive Sciences, 5(3-4), 229-269.

Petitmengin, C., Remillieux, A., \& Valenzuela-Moguillansky, C. (2019). Discovering the structures of lived experience. Phenomenology and the Cogn Sciences, 18, 691-730.

Potter, C. (2008). Sense of Motion, Senses of Self: Becoming a Dancer. Ethnos, 73(4), 444-465.

Ravn, S. (2009). Sensing movement, living spaces - An investigation of movement based on the lived experience of 13 professional dancers. VDM Verlag, Dr. Müller.

Ravn, S, (2010). Sensing weight in movement. Journal of Dance and Somatic Practices, 2(1):21-34.

Ravn, S. (2016). Phenomenological analyses. In B. Smith \& A. Sparkes (Eds.), International handbook of qualitative methods in sport and exercise (pp. 206-218). Routledge.

Ravn, S. (2017a). On the second-person method: Considering the diversity and modes of subjects' descriptions. Open review response to the target article: 'Varela's radical proposal: How to embody and open up cognitive science' by K. Martiny. Constructivist Foundations, 13(1), 81-83.

Ravn, S. (2017b). Dancing practices: Seeing and sensing the moving body. Body \& Society, 23(2), 57-82.

Ravn, S., \& Christensen, M. K. (2014) Listening to the body? How phenomenological insights can be used to explore a golfer's experience of the physicality of her body. Qualitative Research in Sport, Exercise and Health, 6(4), 462-477.

Ravn, S., \& Hansen, H. P. (2013). How to explore dancers' sense experiences? A study of how multisited fieldwork and phenomenology can be combined. Qualitative Research in Sport, Exercise and Health, 5, 196-213.

Ravn, S., \& Høffding, S. (2016). The promise of 'sporting bodies' in phenomenological thinking - how exceptional cases of practice can contribute to develop foundational phenomenological concepts. Qualitative Research in Sport, Exercise and Health, 9(1), 56-68.

Ravn, S., \& Høffding, S. (under review). Improvisation and thinking in movement: An enactivist analysis of agency in artistic practices. Phenomenology and the Cognitive Sciences.

Rouhiainen, L. (2003). Living transformative lives. Theatre Academy.

Sheets-Johnstone, M. (2012). From movement to dance. Phenomenology and the Cognitive Sciences, 11, 39-57.

Schmicking, D. (2010). A toolbox of phenomenological methods. In S. Gallagher and D. Schmicking, eds. Handbook of phenomenology and cognitive science. Springer.

Smith, B., \& Sparkes, A. C. (Eds.). (2016). Routledge Handbook of Qualitative Research in Sport and Exercise. Routledge.

Smith, B., \& Sparkes, A. C. (2016). Introduction: an invitation to qualitative research. In B. Smith \& A. Sparkes (Eds.), Routledge Handbook of Qualitative Research in Sport and Exercise. (pp. 9-11). Routledge.

Strauss, S. (2000). Locating yoga: Ethnography and transnational practice. In V. Amit (Ed.): Constructing the Field (pp. 162-194). Routledge.

Taylor, S. J., \& Bogdan, R. (1998). Introduction to Qualitative Research Methods. A Guidebook and Resource. (3rd ed.). Wiley.

Thompson, E. (2016). Introduction to the revised edition. In F. J. Varela, E. Thompson, and E. Rosch, The Embodied Mind - Cognitive Sciences and Human Experience - revised edition of the 1991 version (pp. xvii- xxxiii). The MIT Press.

Thorpe, H. (2012). The Ethnographic (I)nterview in the Sports Field: Towards a Postmodern Sensibility. In K. Young \& M. Atkinson (Eds.), Research in the Sociology of Sport. (Vol. 6, pp. 51-78). Emerald Group Publishing Limited.

Throop, J. C. (2018). Being open to the world. Journal of Ethnographic Theory, 8(1/2), 197-210. 
Thorpe, H., \& Olive, R. (2016). Conducting observations in sport and exercise settings. In B. Smith \& A. Sparkes (Eds.), International handbook of qualitative methods in sport and exercise (pp. 124-138). Routledge.

Tracy, S. J. (2010). Qualitative quality: eight "big tent" criteria for excellent qualitative research. Qualitative Inquiry, 16(10), 837-851.

Varela, F. J., \& Shear, J. (1999). First-person methodologies: What, why, how? Journal of Consciousness Studies, 6(2-3), 1-14.

Varela, F. J., Thompson, E. \& Rosch, E. (2016) The Embodied Mind - Cognitive Sciences and Human Experience. (revised edition of the 1991 version). The MIT Press.

Young, I. M. (2005). On female body experience: "Throwing Like a Girl" and other essays. Oxford University Press.

Zahavi, D. (1999). Self-awareness and alterity: A phenomenological investigation. Northwestern University Press.

Zahavi, D. (2005). Subjectivity and selfhood: Investigating the first-person perspective. MIT press.

Zahavi, D. (2011). Varieties of reflection. Journal of Consciousness Studies, 18(2), 9-19.

Zahavi, D. (2013). Naturalized phenomenology: A desideratum or a category mistake. Royal Institute of Philosophy Supplement, 72, 23-42.

Zahavi, D. (2015). You, me and we: the sharing of emotional experiences. Journal of Consciousness Studies, 22(1-2), 84-101.

Zahavi, D. (2019a). Getting it quite wrong: Van Manen and Smith on phenomenology. Qualitative Health Research, 29(6), 900-907.

Zahavi, D. (2019b). Applied phenomenology: Why it is safe to ignore the epoché. Continental Philosophy Review. Published online $19^{\text {th }}$ of April, 2019.

Zahavi, D., \& Martiny, K. M. M. (2019). Phenomenology in nursing studies: New Perspectives. International Journal of Nursing Studies, 93, 155-162.

Zahavi, D., \& Rochat, P. (2015). Empathy $\neq$ sharing: Perspectives from phenomenology and developmental psychology. Consciousness and Cognition, 36, 543-553.

Publisher's note Springer Nature remains neutral with regard to jurisdictional claims in published maps and institutional affiliations. 